\title{
Hypoxic ventilatory defence in very preterm infants: attenuation after long term oxygen
} treatment

\author{
Miriam Katz-Salamon, Hugo Lagercrantz
}

\begin{abstract}
The activity of peripheral chemoreceptors was studied in 19 preterm very low birthweight infants at the postconceptional age of 36 and 40 weeks using the hyperoxic test. The infants were in a healthy condition and did not receive any extra oxygen or medication when tested. The inhalation of pure oxygen caused a decrease in mean (SE) ventilation by $16 \cdot 1(2 \cdot 6) \%$ and $15 \cdot 1$ $(2 \cdot 1) \%$ at the 36th and 40th gestational week respectively. At the 36th gestational week the ventilatory response was significantly slower than at 40 weeks $(10.9$ (6) and $7 \cdot 3$ (3) sec). Six infants who had been on supplemental oxygen for more than 21 days (from 21 to 56 days) responded with significantly lower response to hyperoxia at the 36th gestational week $(-7.9(3.6) \%)$ than those receiving oxygen treatment for a shorter period of time, 0 to 16 days $(-19.9(3 \cdot 2) \%)$. The 'low responding' group included three infants who had suffered from chronic lung disease. Those infants showed the lowest hyperoxic response $(-4.3(3 \cdot 9) \%)$. There was no difference in the response among healthy preterm infants (eight infants) and infants with respiratory distress syndrome. At the 40th gestational week the differences, even though showing the same characteristics, were not statistically significant. No statistically significant relationship was found between the strength of the ventilatory response to oxygen versus gestational, postnatal age, nor the time interval between the termination of supplemental oxygen treatment and the test. No relationship was found between the number of apnoeic/bradycardic spells and the strength of the ventilatory depression caused by hyperoxia. In conclusion we found that the very preterm infants, with the exception of those who received long periods of oxygen treatment, have stronger peripheral chemoreceptor responses than those reported for 2-4 day old full term infants. However, infants who had suffered from chronic lung disease show a depressed hyperoxic response.

(Arch Dis Child 1994; 70: F90-F95)
\end{abstract}

The peripheral chemoreceptors play a crucial part in the defence against hypoxia and in the control of breathing. ${ }^{12}$ They have been found to be adapted to the low intrauterine oxygen tension $\left(\mathrm{Po}_{2}\right)$ levels and do not react until $\mathrm{Po}_{2}$ drops below $5 \mathrm{kPa}$, as shown in the sheep fetus. ${ }^{3}$ It has been demonstrated in newborn sheep, rats, and man, during the first days after birth, that the receptors reset to the higher $\mathrm{PO}_{2}$ of the extrauterine environment. ${ }^{3-5}$ Older preterm infants have been reported to react to hypoxia in the same manner as adult man. ${ }^{6}$ When the peripheral chemoreflex was tested by using a single breath of $100 \%$ oxygen a similar response was observed at 1,2, and 3 months of age in full term infants. ${ }^{7}$ The postnatal changes of the chemoreflexes in the newborn rat are attributed to a decrease in dopamine turnover ${ }^{8}$ However, the postnatal adjustment of the chemoreflex can be delayed by chronic hypoxia ${ }^{8}$ possibly due to a sustained high dopamine turnover. ${ }^{89}$

The aim of this study was to investigate to what extent preterm extrauterine life affects the maturation of the peripheral chemoreceptors in infants. We studied the function of peripheral chemoreceptors in very preterm low birthweight infants in relation to: (a) gestational and postnatal age, (b) the duration and character of ventilatory and oxygen treatment, and (c) the maturity of the respiratory control mechanisms reflected by the incidence of recurrent apnoea. ${ }^{1011}$

As the inhalation of hyperoxic gas causes an almost immediate fall in minute ventilation, due to suppression of a chemoreceptor oxygen drive, the inhalation of pure oxygen has been used to gauge the response to hypoxia. ${ }^{12}$

\section{Subjects and methods}

SUBJECTS

Nineteen infants from the neonatal unit at the Karolinska Hospital born at 24-34 gestational weeks (mean (SD) $28 \cdot 8(2 \cdot 7)$ weeks), weighing 711-1482 $\mathrm{g}$ at birth $(1098.6(251 \cdot 6) \mathrm{g})$, were studied at the 36th and 40th week of gestation (see table). All but two infants needed ventilatory support, that is treatment on ventilator or continuous positive air way pressure. Seven infants had respiratory distress syndrome, five had transient tachypnoea, and eight recurrent apnoea that required treatment with theophylline. Three infants had chronic lung disease defined as the requirement for supplemental oxygen for more than 28 days and by specific radiographic findings. One infant with transient tachypnoea required oxygen treatment for 56 days because of several instances of septicaemia. At the time of the examination, however, no infant was receiving oxygen or theophylline treatment. The postnatal age at the first test was $50.7(4.5)$ days. Informed consent from the 
Clinical data on infants studied

\begin{tabular}{|c|c|c|c|c|c|c|c|}
\hline \multirow[b]{2}{*}{$\begin{array}{l}\text { Subject } \\
\text { No }\end{array}$} & \multirow[b]{2}{*}{$\begin{array}{l}\text { Gestational } \\
\text { age at birth } \\
\text { (weeks) }\end{array}$} & \multirow[b]{2}{*}{$\begin{array}{l}\text { Birth } \\
\text { weight } \\
\text { (g) }\end{array}$} & \multirow[b]{2}{*}{$\begin{array}{l}\text { Duration of } \\
\text { oxygen } \\
\text { treatment } \\
\text { (days) }\end{array}$} & \multirow[b]{2}{*}{$\begin{array}{l}\text { No of } \\
\text { apnoeas }\end{array}$} & \multicolumn{2}{|c|}{$\begin{array}{l}\text { Oxygen response (\% of } \\
\text { control) }\end{array}$} & \multirow[b]{2}{*}{$\begin{array}{l}\text { Respiratory } \\
\text { morbidity }\end{array}$} \\
\hline & & & & & $\begin{array}{l}36 \\
\text { gestational } \\
\text { weeks }\end{array}$ & $\begin{array}{l}40 \\
\text { gestational } \\
\text { weeks }\end{array}$ & \\
\hline 1 & 24 & 727 & 53 & 0 & -7 & -13 & CLD, AR \\
\hline 2 & 28 & 802 & 21 & 4 & $-8 \cdot 5$ & $-10 \cdot 5$ & RDS \\
\hline 3 & 30 & 1280 & 13 & 110 & $-4 \cdot 0$ & $-24 \cdot 0$ & TTN, AR \\
\hline 4 & 32 & 1450 & 8 & 17 & -29 & -22 & RDS \\
\hline 5 & 27 & 799 & 39 & 0 & $3 \cdot 5$ & -15 & CLD \\
\hline 6 & 28 & 990 & 16 & 9 & -27 & 3 & Healthy \\
\hline 7 & 25 & 991 & 56 & 24 & -30 & $-2 \cdot 0$ & TTN \\
\hline 8 & 26 & 1021 & 4 & 62 & $-21 \cdot 5$ & -18 & RDS, AR \\
\hline 9 & 32 & 879 & 3 & 0 & -37 & -17 & TTN \\
\hline 10 & 29 & 1482 & 16 & 87 & -17 & -5 & RDS, AR \\
\hline 11 & 32 & 1028 & 1 & 0 & $-11 \cdot 5$ & -18 & TTN \\
\hline 12 & 32 & 1456 & 1 & 0 & $-22 \cdot 0$ & -14.5 & TTN \\
\hline 13 & 30 & 1139 & 9 & 56 & -12 & -35 & RDS, AR \\
\hline 14 & 34 & 1401 & 0 & 1 & -21 & $-8 \cdot 5$ & Healthy \\
\hline 15 & 26 & 1149 & 50 & 187 & $-9 \cdot 5$ & -7 & CLD, AR \\
\hline 16 & 27 & 1190 & 29 & 5 & -35 & -2 & RDS \\
\hline 17 & 28 & 711 & 1 & 0 & -5 & -1.5 & AR \\
\hline 18 & 29 & 1079 & 13 & 0 & -27 & -28 & RDS \\
\hline 19 & 28 & 1049 & 5 & 110 & -8 & -13 & $\mathrm{RDS}, \mathrm{AR}$ \\
\hline
\end{tabular}

$\mathrm{AR}=$ apnoea repetans; ${ }^{\star} \mathrm{CLD}=$ chronic lung disease; $\mathrm{RDS}=$ respiratory distress syndrome; TTN=transient tachypnoea. humidified oxygen for 30 seconds. Thereafter the oxygen was substituted by air. After a period of 5-10 minutes the test was repeated.

\section{ANALYSIS OF THE RESULTS}

The recordings were only considered satisfactory for analysis if the baby remained in the same position, was not startled, and the sleep state did not change.

\section{Response to hyperoxia}

Tidal volume, breath duration, and minute ventilation (tidal volume $\times$ respiratory rate) were analysed on a breath by breath basis for each individual. The ventilatory parameters were calculated during 30 seconds of air breathing before the hyperoxic test and during 30 seconds of oxygen administration. The mean value from two trials was calculated and used for the analysis. Percentage changes in tidal volume, breath duration, and minute ventilation from normoxic to hyperoxic conditions were determined for each infant and tested for significance by Student's $t$ test. The study was approved by the local ethical committee at the Karolinska Hospital.

\section{RESPIRATORY RECORDINGS}

Oxygenation was measured by a pulse oximeter probe (Respitrace, Studley Data System, Oxford). Ventilatory measurements were made with a Greer Electrospirometer CS5 (Mercury Electronics, Scotland). A pneumotachograph was connected to a facemask. The system was calibrated with 5,10 , and $20 \mathrm{ml}$ syringes of warmed, humidified air and oxygen. The flow head was connected via a $T$ tube to a stream of 4 litres/min humidified, warmed air which could be rapidly switched to the 4 litres/min $100 \%$ humidified oxygen. The dead space of the mask, flow head, and tubing was $2-3 \mathrm{ml}$ and the resistance $5 \mathrm{~cm} \mathrm{H} / \mathrm{O} / \mathrm{l} / \mathrm{min}$. The carbon dioxide build up in the spirometric system and the inspired and expired carbon dioxide were analysed at the end of the hyperoxic test with an infrared carbon dioxide analyser (AMETEK CD-3A) sampling gas from the mask at $500 \mathrm{ml} / \mathrm{min}$. Movements of the chest and the abdomen were recorded by inductance plethysmography (Respitrace). The flow signal, its integral tidal volume, movements of the chest and abdomen, inspired and expired carbon dioxide were recorded on an eight channel inkjet recorder.

\section{EXPERIMENTAL PROCEDURE}

The pulse oximeter probe was taped to the infant's foot while the infant was wrapped in blankets in its cot. All examinations were performed in quiet sleep characterised by the absence of eye and body movements and by regular respiration. ${ }^{13}$ The facemask was gently placed on each infant's face. The experimental trial consisted of a period of 3-5 minutes of stable breathing with warmed, humidified room air. Thereafter the inspiratory line was rapidly switched and the infant breathed $100 \%$

\section{Profile of the hyperoxic response}

The response time to the administration of $100 \%$ oxygen was estimated as follows: breathby-breath data were split into groups of two breaths. The response time was defined as the time elapsed between the start of hyperoxic challenge and the first statistically significant change in ventilation (analysis of variance). The results from 36th and 40th gestational week infants were compared.

Relationships between the hyperoxic response and the neonatal status of the infant

The hyperoxic changes in ventilation, tidal volume, and breath duration were related to: (a) the postnatal age and the amount of apnoeic/bradycardic episodes, (b) the length of ventilatory treatment, (c) the duration $(1,2,3$, and 4 weeks) and the intensity of supplemental oxygen treatment (median concentrations), (d) the time elapsed from the termination of oxygen treatment, and (e) results from blood samples $\left(\mathrm{PO}_{2}\right)$ (multiple regression analysis and/or Spearman rank correlation).

\section{Results}

Oxygen saturation during air breathing and $100 \%$ oxygen varied between $92 \%-96 \%$ and $98 \%-99 \%$ respectively. The accumulation of carbon dioxide at the end of the hyperoxic test ranged from $0 \cdot 2 \%$ to $0 \cdot 4 \%$.

\section{RESPONSE TO HYPEROXIA AT 36TH AND 40TH} GESTATIONAL WEEKS

The spontaneous variation in resting ventilation preceding the hyperoxic challenge was 11 (3) $\%$. The mean ventilation at normoxia did not increase significantly ( $p=0.37, t$ test) at the end of the control period in spite of a slight 

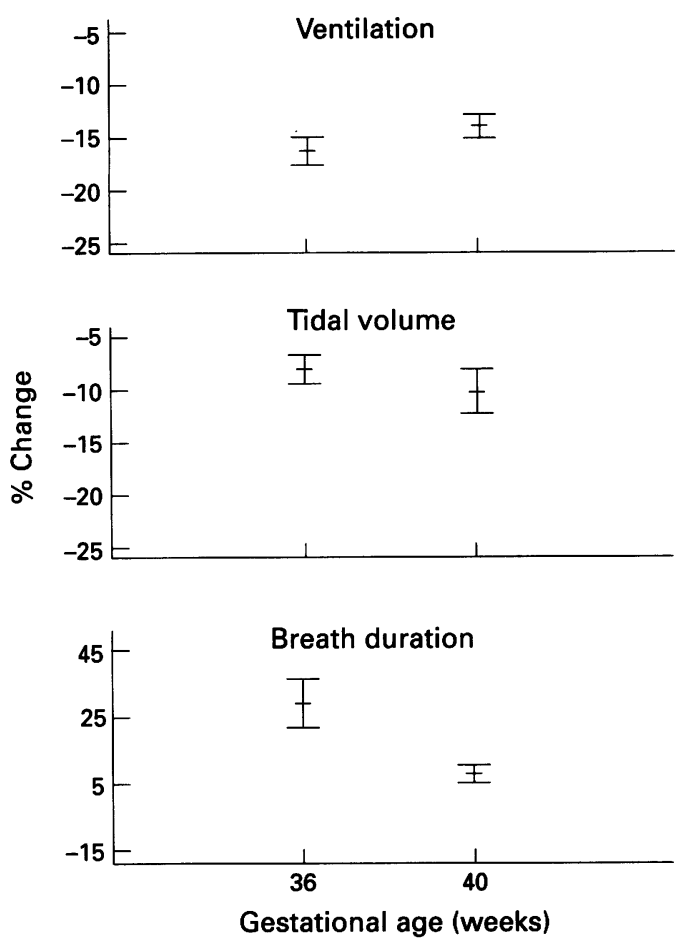

Figure 1 Changes in minute ventilation, tidal volume, and breath duration in response to hyperoxic test expressed as percentage of normoxic values.

increase in carbon dioxide $(0.2 \%-0.4 \%)$ in the spirometric system. Figure 1 shows group data on changes in minute ventilation, tidal volume, and breath duration in response to hyperoxic test. The results are expressed as percentage change from normoxic breathing. At the 36th gestational week minute ventilation decreased by mean (SE) $16 \cdot 1(2 \cdot 6) \%$. In $47 \%$ of all tests this was caused by a decrease in tidal volume alone, whereas a concomitant change in both breath duration and in tidal volume was observed in the other $47 \%$ of the tests. Only in $6 \%$ of the hyperoxic expositions were the changes in ventilation significantly correlated with the increase in breath duration. At the 40th gestational week the ventilation decreased by $15 \cdot 1(2 \cdot 1) \%$. Changes in ventilation were due to changes in tidal volume or to variations in both duration and amplitude of breath. Thus, the strength of the response expressed in percentage changes in ventilation, tidal volume, and breath duration did not alter between the 36 th and 40 th gestational weeks.

PROFILE OF THE HYPEROXIC RESPONSE

Changes in breathing patterns caused by hyperoxia were characterised by wide individual variability. In most of the infants, however, the reaction pattern could be described generally either as a depression in ventilation followed by a return to control levels (see fig 2 , patients 3 and 10). In two infants the initial decrease in ventilation was followed by a successive increase and then a decrease (fig 2, patients 4 and 13). In three infants at the gestational age of 36 weeks the hyperoxic inhalation gave rise to a prolonged apnoea of 5-30 seconds. Only one child responded with an apnoea (5 seconds) at the gestational age of 40 weeks. This infant had the most pronounced apnoea (30 seconds) at the 36th gestational week. The response time expressed in seconds and breath passed between the start of oxygen administration and the ventilatory depression was significantly longer $(p=0.01)$ at 36th
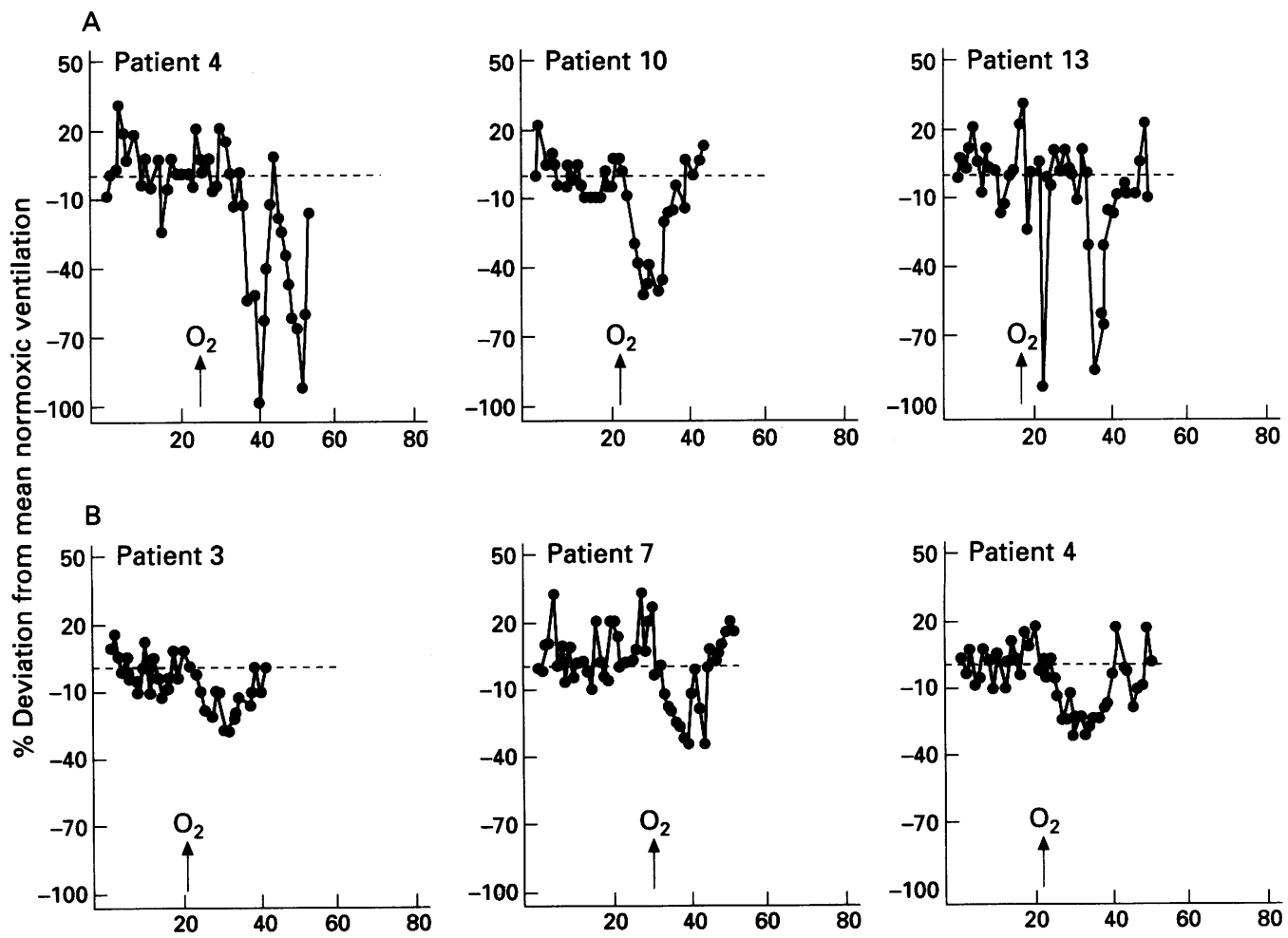

Figure 2 Breath by breath analysis of the ventilatory changes during 30 seconds of normoxic breathing and 30 seconds inhalation of $100 \%$ oxygen at $(A)$ the 36 th and $(B)$ the 40 th gestational week. The arrows indicate the application of $100 \%$ oxygen. 

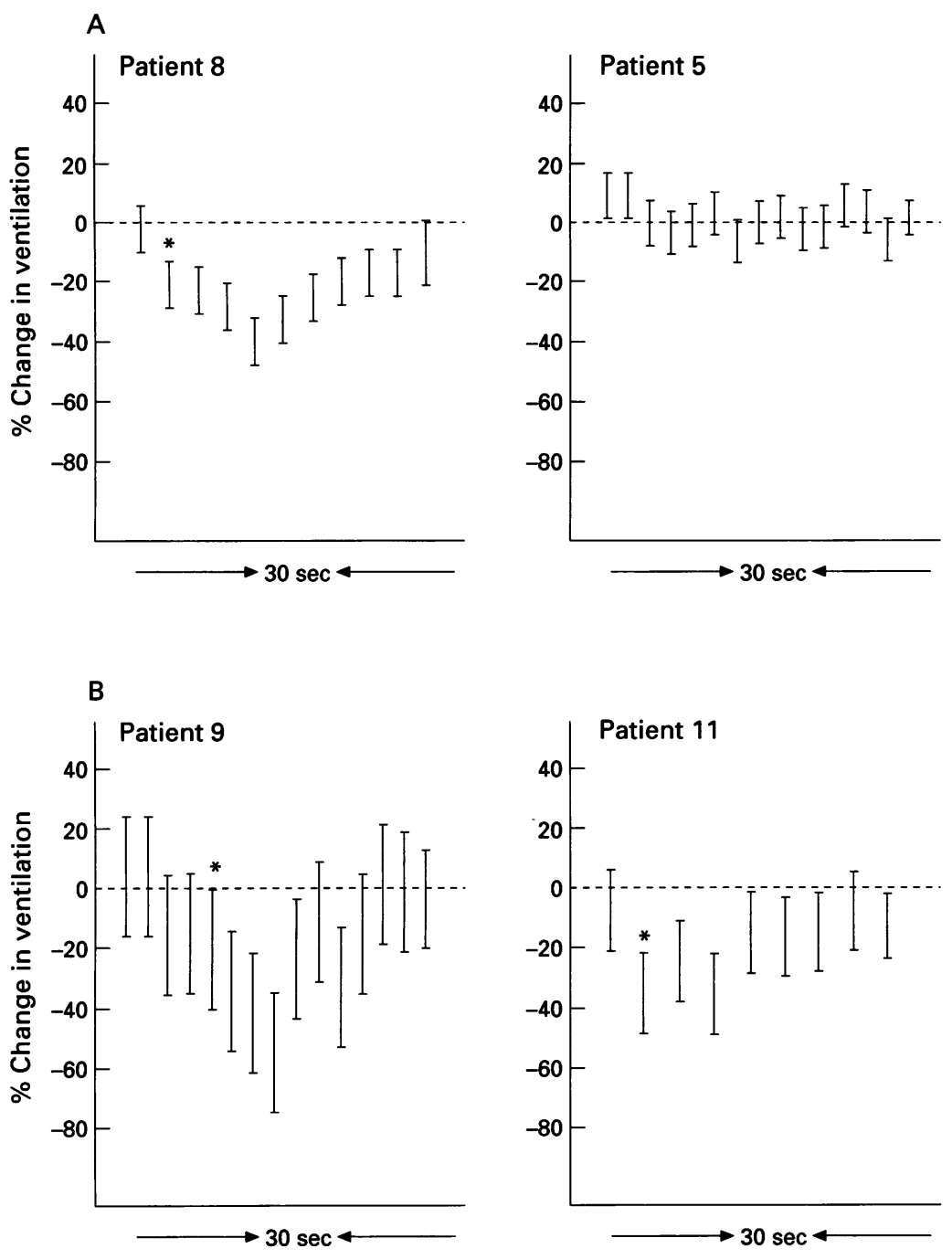

Time

Figure 3 Response time estimated on the basis of significant decrease in ventilation in two consecutive breaths in $(A)$ two patients at the 36 th and $(B)$ two patients at the 40th gestational week. The asterisks indicate a statistically significant difference. In one subject (patient 5) no such a change was seen.

gestational week (10.9 (6) seconds, 10.2 (5) breaths) than at 40 th week of gestation $(7 \cdot 3$ (3) seconds, $6.3(3.3)$ breaths). In two infants there was no significant decrease in ventilation so the response time could not be estimated (see fig 3, patient 5).

\section{POSTNATAL AGE AND RESPIRATORY RESPONSE} TO HYPEROXIA

The postnatal age at gestational week 36th varied from 14 to 86 days (mean 51 (20) days). There was no statistically significant
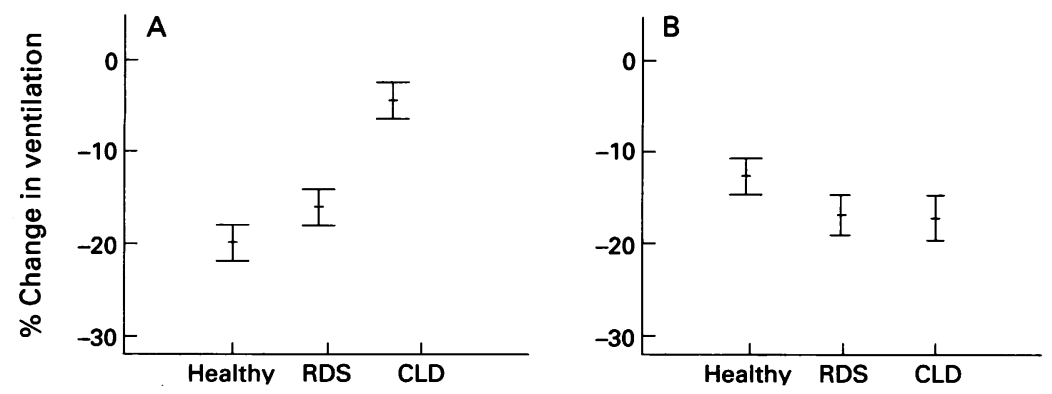

Figure 4 Ventilatory response to hypoxia at $(A)$ the 36th and $(B)$ the 40 th week of gestation in healthy preterm infants and those with respiratory distress syndrome (RDS) and chronic lung disease (CLD).

correlation between changes in ventilation, tidal volume, and cycle duration in response to hyperoxia and postnatal age.

VENTILATORY RESPONSE TO HYPEROXIA AND OXYGEN CONCENTRATIONS DURING SUPPLEMENTAL OXYGEN TREATMENT

The median values of supplemental oxygen varied from $24 \%$ to $35 \%$. Neither at the 36 th nor the 40th gestational week was there any correlation between oxygen concentrations and the hyperoxic response $(p=0.9$ and $\mathrm{p}=0.27$ respectively).

HYPEROXIC RESPONSE AND THE TIME AFTER END OF OXYGEN TREATMENT

The mean number of days elapsed after the end of oxygen treatment and the hyperoxic test was 26 (13) (from 1-58 days). There was no correlation between the strength of the response and the number of days after withdrawal from oxygen treatment.

\section{HYPEROXIC RESPONSE AND DURATION OF} OXYGEN TREATMENT

The mean length of supplemental oxygen treatment was 18 (19) days (minimum 0, maximum 56 days). When all infants were tested as a group the length of supplemental oxygen treatment did not affect the ventilatory hyperoxic response (Spearman rank correlation coefficient, $p=0 \cdot 18$ ). However, when the infant group was split into those who received supplemental oxygen for less than $1,2,3$, and 4 weeks respectively there was a marked difference in the ventilatory response between infants receiving supplemental oxygen for more than 21 days (six infants) and those treated for a shorter period of time (14 infants). At the 36 th gestational week the mean decrease in ventilation in infants treated with oxygen for more than 21 days was significantly lower $(-7 \cdot 8(12) \%)$ than the ventilatory fall in the other group $(-19.9(8.4) \%)$. At the 40 th gestational week the infants dependent on supplemental oxygen for more than 21 days still had a lower response to hyperoxia $(-10 \cdot 4$ (11)\%) than infants treated with oxygen for a shorter period of time $(-17 \cdot 2(7) \%)$ but the difference was not statistically significant.

\section{HYPEROXIC RESPONSE AND THE RESPIRATORY} MORBIDITY

At the 36th week of gestation both healthy preterm infants (eight infants) and those with respiratory distress syndrome (eight infants) had significantly higher response than infants who had suffered from chronic lung disease $(-20 \cdot 6 \%,-16 \cdot 1 \%$, and $-4.3 \%$ respectively; see fig 4 ).

HYPEROXIC RESPONSE AND THE STABILITY (MATURITY) OF VENTILATORY CONTROL The stability of respiration measured by the number of apnoeic/bradycardic spells (33 (49) 
episodes) was not correlated to the strength of the hyperoxic response (Spearman rank correlation test). When the capillary $\mathrm{PO}_{2}$ was analysed, the results showed significantly higher variations in $\mathrm{PO}_{2}$ in infants who required supplemental oxygen for more than 21 days than in those with a shorter duration of oxygen treatment $(p=0.029)$.

\section{Discussion}

The general principle of 'physiological denervation' of peripheral chemoreceptors by the inhalation of $100 \%$ oxygen, used in this study, was outlined by Dripps and Comroe in $1947^{12}$ and used for the first time by Girard and Dejours in newborn infants in $1969^{14}$ and later on by a number of other groups. ${ }^{15} 16$ The hyperoxic 'denervation' of peripheral chemoreceptors can be accomplished by breath-bybreath alternating exposure to $100 \%$ oxygen or longer lasting inhalation of $100 \%$ oxygen (between 30 seconds and 5 minutes). In the present study we decided to use 30 seconds of exposure to $100 \%$ oxygen for several reasons. As described elsewhere, ${ }^{17} 18$ even normal preterm infants show an unevenness in the ratio between alveolar ventilation and vascular perfusion $\left(V_{A} / Q\right)$, whereas in infants with respiratory distress syndrome and chronic lung disease the value of $\mathrm{V}_{\mathrm{A}} / \mathrm{Q}$ is even more disturbed due to the maldistribution and reduction of the perfusion area. This may be of some concern with respect to the possible effect of the facemask on the breathing pattern, which may in turn influence the ventilatory response to hyperoxia. As shown in our previous paper, ${ }^{19}$ however, the application of a facemask causes only temporary changes in the breathing pattern, which disappear within $40-50$ breaths. As the ventilatory response to hyperoxia was measured after 3-5 minutes of breathing through a facemask, the possible effect of the spirometric device on the respiratory response could be excluded. The small retention of carbon dioxide $(0 \cdot 2-0.4 \%)$ in the spirometric system did not influence the response as the ventilation at the beginning and end of air breathing did not change.

The group of preterm infants investigated in this study represented a clinically heterogeneous group, with seven infants who had had respiratory distress syndrome, five with transient tachypnoea, three with chronic lung disease, and eight with recurrent apnoea. By using 30 seconds of continuous stimulation with oxygen instead of the alternate breath method we excluded the risk of insufficient stimulation of the peripheral chemoreceptors due to a delayed response time caused by structural differences in the infants' lungs. This duration is also assumed to be sufficient to avoid the effect of hyperoxia on central respiratory control mechanisms. ${ }^{20}$

Almost all preterm infants showed a decrease in ventilation when subjected to $100 \%$ oxygen in accordance with previous studies. The decrease in ventilation for the whole group as well as for the healthy preterm infants was almost the same at the 36th and 40th gestational week. The healthy preterm infants showed a much higher hyperoxic response $(-20.3 \%)$ than healthy newborn term infants $(-9.8 \%)$ tested by the same method at the age of 2-4 days. ${ }^{20}$ These findings indicate that the tonic peripheral chemoreceptor drive during normoxia is higher in preterm than in term infants. This is in agreement with earlier studies. ${ }^{1521}$ The high hyperoxic sensitivity found in preterm infants has been suggested to be due to a low $\mathrm{Po}_{2} \cdot{ }^{6} \mathrm{It}$ seems to be less likely that the increased chemoreceptor drive is due to a lower resting $\mathrm{PO}_{2}$. This would instead lead to a lower drive as chronic hypoxia lowers the set point. ${ }^{89}$

The decrease in ventilation in infants in this study was achieved mainly by a highly significant decrease in tidal volume only or by simultaneous changes in breath duration and amplitude. A similar outcome was reported by Aizad et al. ${ }^{15}$ In three infants, however, the hyperoxic inhalation resulted in apnoeas of 4 to $30 \mathrm{sec}$ in duration. Neither the strength of the response nor the breathing pattern was correlated with the infants' postnatal age and the duration of ventilatory treatment. This is in contrast with the results obtained by Alvaro et al in preterm infants at gestational week 29; they described a profound decrease in respiratory rate associated with hyperoxic inhalation. ${ }^{22}$

As shown in our study there was no correlation between the maturity in ventilatory control, expressed by the frequency of apnoeic spells and the strength of the hyperoxic response. These results are in agreement with findings by Glotzbach et al, who were unable to find any significant relations between periodic breathing and chemoreceptor activity. ${ }^{23} \mathrm{We}$ must be aware, however, of the fact that not all hypoxic spells are recognised in the neonatal ward and that the number of apnoeic episodes is likely to be underestimated and thus not very reliable as a measurement of the maturity of ventilatory control mechanisms. ${ }^{24}$

We did not find any correlation between the hyperoxic response and the postnatal age, which at the 36th gestational week varied between 14 and 86 days (mean 50.7 (4) days). Our results support the proposal that the peripheral chemoreceptors mature within three weeks after birth. ${ }^{56}$

The profile of the ventilatory response to hypoxia was characterised by individual variability. Most infants reacted with a decrease in ventilation and a recovery to normoxic ventilation. Only three infants showed an alternating hypoventilation followed by an increase in ventilation when subjected to hyperoxic breathing, as described by Alvaro et al. ${ }^{22}$

The most striking finding in this study is the significantly lower hyperoxic response in infants tested at gestational week 36 who were dependent on supplemental oxygen for more than 21 days (including three infants who had chronic lung disease and one infant who was receiving supplemental oxygen for 56 days because of several instances of septicaemia) than in infants receiving supplemental oxygen for less than 21 days. When tested at 
gestational week 40 the response was still lower, but the difference was not statistically significant. The indication for oxygen treatment was desaturation (oxygen saturation $<85 \%$ ) when breathing room air.

One possible explanation for these findings is that the oxygen breathing has attenuated the hyperoxic reflex. We believe, however, that these infants sustained hypoxic episodes and, as a consequence, the peripheral chemoreceptors were set at a lower sensitivity. The significantly higher variations in blood gases in infants requiring longer oxygen treatment also indicates an instability in ventilatory control. Our findings are corroborated by the observation that newborn rats exposed to postnatal hypoxia were found to have a weak chemoreflex. ${ }^{89}$

The latency of the ventilatory response to hyperoxia is mainly due to the circulation time from the alveoli to arterial chemoreceptors. This study has shown a significantly longer latency in the response to hyperoxia at the 36th gestational week compared with the 40th week of gestation. It may be suggested that the differences in latency could be due to dissimilarities in circulation time. The circulation time is very short $(1 \mathrm{ml} / \mathrm{sec})$, however, and therefore seems unlikely to influence the reaction time of several seconds in duration. An alternative explanation seems possible. The adequate adaptation of respiration to changes in metabolic demands is based on an intricate interaction between the activity of the peripheral chemoreceptors and central respiratory control mechanisms. Arterial chemoreceptors afferents are known to excite respiratory neurones via specific pathways, ${ }^{24}$ whereas counteracting descending pathways inhibit stimulatory effects of peripheral chemoreceptors. ${ }^{25}$ Brainstem and the higher central nervous system levels play a crucial part in the control of breathing. The fact that synaptic conductivity is not yet mature ${ }^{26} 27$ may explain the longer reaction time to hyperoxic challenge at the 36th gestational week.

This study has shown that the three infants who had chronic lung disease belonged to the group of 'low responders'. It would therefore be of great clinical interest to study further the hyperoxic response in this group as the deficient hypoxic response might contribute to the high prevalence of sudden infant death syndrome among infants who have had chronic lung disease during the neonatal period. ${ }^{28}$

The authors are grateful to Dr $\mathbf{M}$ Bonora and Professor $\mathrm{H}$ Gautier for reviewing the manuscript. The study was supported by grants from the Bank of Sweden Tercentenary Foundation, Swedish Heart and Lung Foundation, Swedish MRC 5234 and the AGA foundation.

1 Blanco CE, Dawes GS, Hanson MA, McCooke HB. The response to hypoxia of arterial chemoreceptors in fetal sheep and new-born lambs. 7 Physiol 1984; 351:25-37.

2 Honda $Y$. Role of cartid chem breathing at rest and in exercise: studies on human subjects with bilateral carotid body resection. $\mathcal{f}$ Physiol 1985; 35: $535-44$.
3 Hanson MA. Peripheral chemoreceptor function before and after birth. In: Johnston BM, Gluckman PD, eds. Respiratory control and lung development in the fetus and newborn. Reproductive and perinatal medicine. Ithaca, NY Perinatology Press, 1986: 311-30.

4 Bureau MA, Begin R. Postnatal maturation of the respiratory response to $\mathrm{O}_{2}$ in awake newborn lambs. $\mathcal{f} A p p l$ Physiol 1982; 52: 428-33.

5 Henderson-Smart DJ, Cohen GL. Regulation of breathing and apnea in newborn infant. In: Johnston BM, Gluckman PD, eds. Respiratory control and lung development in the fetus and newborn. Reproductive and perinatal medicine. Ithaca, NY: Perinatology Press, 1986: 397-421.

6 Regatta H, Brady JP, Torre Verduzco R del. Chemoreceptor refluxes in preterm infants. I. The effect of gestational age on the ventilatory response to inhalation of $100 \%$ and $15 \%$ oxygen. Pediatrics $1975 ; 55$ 604-13.

7 Parks YA, Beardsmore CS, MacFadyen UM, et al. The effect of a single breath of $100 \%$ oxygen on breathing in infants at 1,2 and 3 months of age. Am Rev Respir Dis 1991; 144: 141-5.

8 Hertzberg $T$, Hellström S, Holgert $H$, Lagercrantz $H$, Pequignot JM. Ventilatory response to hyperoxia in newborn rats born in hypoxia - possible relationship to carotid born rats born in hypoxia - possible relationship

9 Hanson MA, Kumar P, Williams BA. The effect of chronic hypoxia upon the development of respiratory chemoreflexes in newborn kitten. F Physiol 1989; 411: 563-74.

10 Gerhardt T, Bancalari E. Apnea of prematurity: I. Lung function and regulation of breathing. Pediatrics 1984; 74 58-62.

11 Lee D, Caces R, Kwiatkowski K, Cates D, Rigatto H. A developmental study on types and frequency distribution of short apneas ( 3 to 5 seconds) in term and preterm infants. Pediatr Res 1987; 22: 344-9.

12 Dripps $\mathrm{RD}$, Comroe JH Jr. The effect of the inhalation of high and low oxygen concentrations on respiration, pulse rate, ballisto-cardiogram, and arterial oxygen saturation (oximeter) of normal individuals. Am $\mathcal{F}$ Physiol 1947; 149: 277.

13 Prechtl HV. The behavioral states of the newborn infant (a review). Brain Res 1974; 76: 185-212.

14 Girard FL, Dejours R. Le stimulus $\mathrm{O}_{2}$ ventilatoire a' la periode neonatale chez l'homme. $f$ Physiol 1969; 52: 108-9.

15 Aizad TB, Cates J, Horvath DL, Rigatto H. Effect of single breath of $100 \%$ oxygen on respiration in neonates during sleep. F Appl Physiol 1984; 57: 1531-5.

16 Sankaran K, Wiebe H, Seshia MK, Boychuk RB, Cates D, Rigatto $\mathrm{H}$. Immediate and late ventilatory response to high and low $\mathrm{O}_{2}$ in preterm infants and adult subjects. high and low $\mathrm{O}_{2}$ in preterm
Pediatr Res $1979 ; 13: 875-8$.

17 Auld PA. Pulmonary physiology of the newborn infants. In: Scarpelli MM, Febiger L, eds. Pulmonary physiology of the fetus, newborn and child. Philadelphia: 1975.

18 Gorenflo M, Vogel M, Obalden M. Pulmonary vascular changes in bronchopulmonary dysplasia: a clinicopathologic correlation in short- and long-term survivors. Pediat Pathol 1991; 11: 851-66.

19 Katz-Salamon M, Hertzberg T, Lagercrantz $\mathrm{H} . \mathrm{CO}_{2}$-sensitivity in newborn and young infants tested by the rebreathing method. Methodological aspects. Biol Neonate 1991; 59: 126-32.

20 Hertzberg T, Lagercrantz $H$. Postnatal sensitivity of the peripheral chemoreceptors in newborn infants. Arch Dis Child 1987; 62: 1238-41.

21 Cross KW, Oppe TE. The effect of inhalation of high and low concentrations of oxygen on the respiration of the premature infant. F Physiol 1952; 117: 38-55.

22 Alvaro RE, Weintraub Z, Kwiatkowski K, Cates DB Rigatto $H$. Speed and profile of the arterial peripheral chemoreceptors as measured by ventilatory changes in preterm infants. Pediatr Res 1992; 32: 226-9.

23 Glotzbach SF, Tansey PA, Baldwin RB, Ariagno RL Periodic breathing cycle duration in preterm infants. Pediatr Res 1989; 25: 258-61.

24 Upton CJ, Milner AD, Stokes GM. Apnoea, bradycardia, and oxygen saturation in preterm infants. Arch Dis Child 1991; 66: 381-5.

25 Ungar A, Bouverot $P$. The ventilatory responses of conscious dogs to isocapnic oxygen tests. A method of exploring the central component of respiratory drive and its dependence on $\mathrm{O}_{2}$ and $\mathrm{CO}_{2}$. Respir Physiol 1980; 39: 183-97.

26 Martin-Body RL, Johnston BM. Central origin of hypoxic depression of breathing in the newborn. Respir Physiol 1988; 71: 25-32.

27 Henderson-Smart DJ, Pettigrew AG, Campbell DJ. Clinical apnea and brain stem neural function in preterm infants. N Engl f Med 1983; 308: 353-7.

28 Werthammer J, Brown ER, Neff RK, Taeusch HW. Sudden infant death syndrome in infants with bronchopulmonary dysplasia. Pediatrics 1982; 69: 301-4. 